\title{
Diagnosing Parkinson's Disease: The Patient Perspective
}

\author{
Teneille E. Gofton, Mandar Jog
}

Can. J. Neurol. Sci. 2008; 35: 510-512

In Parkinson's disease (PD), quality of life research has focused on medical therapeutics and management of physical symptoms. Physical mobility, sleep, energy, difficulty with activities of daily living and pain are important contributors to quality of life. ${ }^{1}$ Emotional reactions and disease related social isolation also contribute to the patient experience of PD. ${ }^{1}$ Little is known, however, about how patients deal with a new diagnosis of PD.

Haines et al explored the time at which patients with PD reveal their diagnosis to others. ${ }^{2}$ Ninety percent of patients disclosed their diagnosis to family within one month. However, $25 \%$ of patients waited longer than one year before disclosing the diagnosis of PD to coworkers or employers. A decreased likelihood of disclosure within the first year was associated with being male, younger and employed. ${ }^{2}$ The life context of the patient at the time of diagnosis is also likely to influence disclosure.

Understanding how patients cope with their disease from the outset is fundamental to fostering a supportive patient-physician relationship. We sought to determine whether there is a common initial response amongst patients at the time of diagnosis of PD.

A descriptive cross-sectional study of patients with a diagnosis of PD was undertaken in Southwestern Ontario, Canada. Seventy-nine patients with PD voluntarily participated in this study (ethics approval obtained). A short questionnaire was distributed to all participants asking:

How old were you when you were diagnosed with Parkinson's disease?

What were your personal feelings when you were given the diagnosis of $P D$ ?

An area for a free written response was provided. Patient responses were assessed in a qualitative manner. Analysis was based on previously established methods described by Strauss (1987). ${ }^{3}$ Categories of emotional response were generated based on words and themes included in patient responses. The event rates for each category of patient reaction were calculated.

Seventy-nine patients with variable duration of $\mathrm{PD}$ participated. The five most common initial reactions to the diagnosis of PD were 1) frightened for the future $(26.6 \%$; including feeling nervous, concerned for the future, concerned regarding finances or employment); 2) shock (24.1\%; including surprised, stunned); 3) sadness or depression (24.1\%; including feelings of despair, grief, disappointment, devastation); 4) denial (20.3\%; including being unable to accept the diagnosis or disbelief) and; 5) relief (16.5\%; including relief in knowing the diagnosis or at being taken seriously). Further responses are summarized in Table 1. Table 2 contains excerpts from patient narratives that were felt to be representative of common responses.

Table 1: Frequency of patient responses to an initial diagnosis of PD

\begin{tabular}{lcc}
\hline Response & $\begin{array}{c}\text { Number of } \\
\text { patients }\end{array}$ & $\%$ \\
\hline Total responses & 79 & 100 \\
frightened for the future & 21 & 26.6 \\
shock & 19 & 24.1 \\
sad or depressed & 19 & 24.1 \\
denial & 16 & 20.3 \\
relief & 13 & 16.5 \\
hopeful and optimistic & 9 & 11.4 \\
motivated to learn more about PD & 9 & 11.4 \\
confirming suspicions of diagnosis & 7 & 8.9 \\
anger & 7 & 8.9 \\
why me? & 7 & 8.9 \\
acceptance & 6 & 7.6 \\
little knowledge of PD & 4 & 5.1 \\
hopelessness & 3 & 3.8 \\
loneliness & 2 & 2.5 \\
self-pity & 1 & 1.3 \\
ashamed & 1 & 1.3 \\
\hline
\end{tabular}

From the Department of Clinical Neurological Sciences, Movement Disorders Program, University of Western Ontario, London, Ontario, Canada.

Received January 21, 2008. Final Revisions Submitted March 13, 2008. Correspondence to: Teneille E. Gofton, Department of Clinical Neurological Sciences, University of Western Ontario, 339 Windemere Road, Room A10-026, London, Ontario, N6A 5A5, Canada. 
Table 2: Excerpts from patient narratives that are representative of common response categories. The age indicated is the age at which the patient was diagnosed with Parkinson's disease. *Asterisk indicates patient age data not available.

\begin{tabular}{|c|c|c|}
\hline Category & Age & Excerpt \\
\hline \multirow[t]{2}{*}{ frightened for the unknown } & 52 & $\begin{array}{l}\text { "On receiving the diagnosis I was very frightened as to what the } \\
\text { future would bring. Reading a book from the library was also scary." }\end{array}$ \\
\hline & 47 & $\begin{array}{l}\text { "How will I deal with PD? What does the future hold? How will this } \\
\text { affect my job? Will I have to quit working?" }\end{array}$ \\
\hline shock & 78 & “...state of shock, I considered myself healthy." \\
\hline \multirow[t]{2}{*}{ sad or depressed } & $*$ & "[I felt] old, scared, out of control...great sadness and grief." \\
\hline & 47 & $\begin{array}{l}\text { "I sat in my truck asking why me? I felt a sudden loss not realizing } \\
\text { what I had just lost...never angry, just a sense of sadness and lost } \\
\text { feeling." }\end{array}$ \\
\hline \multirow[t]{2}{*}{ denial } & 50 & $\begin{array}{l}\text { "I disbelieved I had a disease...emotionally overcome and unable to } \\
\text { concentrate on what the doctor was saying...I was apprehensive about } \\
\text { how the disease would affect my life." }\end{array}$ \\
\hline & 78 & $\begin{array}{l}\text { "It took months and months before I really accepted the diagnosis. } \\
\text { For the longest time I thought, hoped, there had been a big mistake." }\end{array}$ \\
\hline \multirow[t]{3}{*}{ relief } & 75 & $\begin{array}{l}\text { "...relief that symptoms which interfered with my functioning } \\
\text { adequately were finally diagnosed." }\end{array}$ \\
\hline & 62 & $\begin{array}{l}\text { "Finally someone has told me what I have and now [I] can learn how } \\
\text { to treat it." }\end{array}$ \\
\hline & $*$ & $\begin{array}{l}\text { "Relieved to finally know what was causing all my symptoms, right } \\
\text { arm, right leg...so it wasn't a brain tumor or a stroke." }\end{array}$ \\
\hline \multirow[t]{2}{*}{ things patients found helpful } & 52 & $\begin{array}{l}\text { "Over time I became more accepting and comfortable with the } \\
\text { diagnosis. Becoming an informed patient seemed to be helpful." }\end{array}$ \\
\hline & 68 & $\begin{array}{l}\text { "After we got a support group going and had speakers and more } \\
\text { information on PD we felt better about it and it has turned out better } \\
\text { than I expected." }\end{array}$ \\
\hline
\end{tabular}

The manner in which bad news is delivered is paramount to a patient's understanding of the disease, to their future outlook ${ }^{4}$ as well as to their ability to cope with the disease. ${ }^{5}$ Making informed decisions about the future relies on adequate information. A review of the oncology literature by Baile et $\mathrm{al}^{5}$ showed that the delivery of bad news affects comprehension of information, satisfaction with medical care and hopefulness for the future. Baile et al put forth a protocol for breaking bad news (SPIKES) based on patient expectations reported in the literature. The SPIKES protocol includes assessing a patient's perception of the situation, obtaining an invitation for disclosure, warning the patient that bad news is coming, addressing the patient's emotions with empathetic responses and proposing a plan for further therapy as appropriate..$^{5}$

This study was performed retrospectively and therefore has the potential for error. Given that is was also designed as an initial exploratory project, a full set of demographic data were not collected. A prospective study addressing these issues will yield very interesting results. The duration of patient experience with PD over time may also alter a patient's perspective on their initial diagnosis. However, given the life changing nature of a diagnosis of PD, it is likely to be a significant moment in a patient's life and thus remembered vividly. The specific and detailed nature of the patient responses also suggests that diagnosis is a time that patients remember well. The open-ended nature of the questionnaire was advantageous because it required that patients answer with their own words to describe the emotions they were experiencing. This allowed for a more genuine representation of the patient experience.

\section{Conclusions}

Knowing what patients experience will allow clinicians to more effectively respond to a patient's emotional reaction thereby facilitating the delivery of life-altering news and creating as positive an experience as possible. This study serves as a launching point for further research investigating the patient's disease experience in a prospective manner and exploring the various influences, both demographic and otherwise, on this experience. 


\section{ACKNOWLEDGEMENTS}

The authors thank the study participants for their generous participation, and Dr. Valerie Schulz, palliative care physician, at London Health Sciences Centre for her continued guidance and encouragement. No funding was provided for this study.

\section{REFERENCES}

1. Karlsen K, Tandberg E, Arsland D, Larsen J. Health related quality of life in PD: a prospective longitudinal study. J Neurol Neurosurg Psychiatry. 2000;69:584-9.

2. Haines S, Chen H, Anderson K, Fishman P, Shulman L, Weiner W, et al. When do patients with PD disclose their diagnosis? Neurology. 2006;67(3):488-90.

3. Strauss A. Qualitative analysis for social scientists. New York: Cambridge University Press; 1987.

4. Sardell A, Treirweiler S. Disclosing the cancer diagnosis: procedures that influence patient hopefulness. Cancer. 1993; 72:355-65.

5. Baile W, Buckman R, Lenzi R, Glober G, Beale E, Kudelka A. SPIKES - a six-step protocol for delivering bad news: application to the patient with cancer. Oncologist. 2000;5: 302-11. 